\title{
COGNITIVE IMPAIRMENT IN PARKINSON'S DISEASE
}

\section{TO THE EDITOR}

We would like to comment some methodological issues that arised from the interesting paper of Piovesan et al.' and that did not were cleared in the discussion.

As it is known, many antiparkinsonian agents may cause cognitive and psychiatric symptoms, mainly those with anti-cholinergic effects ${ }^{2}$. Piovesan et al. stated that none of the patients in the PWID group (Parkinson Group with depression) were taking medication with a potential anticholinergic effect, but did not mention anything about the parkinson group without depression (PWOD). If PWOD was taking anti-cholinergic drugs, this may have biased some results found in the paper, such as those stated here:

a) "comparison of individuals with and without depression did not reveal any statistically significant data that indicated that depression could have an influence on cognitive function in this group". In other words, parkinsonian patients with depression may have similar cognitive performance just when compared with parkinsonian patients without depression but using anti-cholinergic agents, what will naturally impair the real cognitive potential performance of PWOD group.

b) "the PG group as a whole, rather than just those individuals whose scores indicated that they were depressive, had more obvious cognitive deficits than the CG group". Once more, use of anti-cholinergic drugs may have biased this statement.

Besides that, another antiparkinsonian drugs (excluding this time the anti-cholinergic ones) may cause cognitive and psychiatric symptoms, including depression ${ }^{2}$, thus explaining, at least in part, some discrepancies between the prevalence of depression in the parkinsonian group when compared with controls. Another important issue is that some psychiatric side effects (sleep distur- bance, inapetence, concentration difficulties, disturbed thoghts) of dopaminergic agents may score and contribute to higher pontuations on Montgomery-Asberg scale in Parkinson's Disease (PD).

Finally, we would like to comment on the difficulties related to the diagnosis of depression in PD. Because features of PD frequently overlap with typical manifestations of major affective disorder (or mild dysthymia), diagnosis of this comorbidity is challenging. Some of these interactive features include cognitive and speech deficits and impairments in emotional expression (e.g., PD-related facial masking) or processing ${ }^{3}$. Apathy as well can be extremely difficult to distinguish from depression in PD.

\section{REFERENCES}

1. Piovezan MR, Teive HAG, Piovesan EJ, Mader MJ, Werneck LC. Cognitive function assessment in idiopathic Parkinson's disease. Arq Neuropsiquiatr 2007;65:942-946.

2. Burn DJ, Tröster AI. Neuropsychiatric complications of medical and surgical therapies for Parkinson's disease. J Geriatr Psychiatry Neurol 2004;17:172-180.

3. Poewe W, Luginger E. Depression in Parkinson's disease: impediments to recognition and treatment options. Neurology 1999;52(Suppl 3):S2-S6.

Leonardo Caixeta, Vânia Lúcia Soares, Cândida Dias Soares Cognitive and Behavioral Neurology Unit - Hospital das Clínicas Federal University of Goiás

\section{AUTHORS' REPLY}

We would like, first of all, to thank Caixeta et al. for their interest in our article and for their constructive comments.

We wish initially to clarify that the group of patients suffering from Parkinson's disease without depression were not using antidepressants.

It may not have been clear throughout the article that we took great care to avoid a methodological bias as a re-

Table. Comparison between the groups and subgroups*.

\begin{tabular}{lcccccc}
\hline Groups & $1 \times 2$ & $1 \times 3$ & $2 \times 3$ & $4 \times 5$ & $1 \times 4$ & $1 \times 5$ \\
\hline MADRS & $\mathrm{P}=0.009$ & $\mathrm{P}=0.001$ & $\mathrm{P}=0.712$ & $\mathrm{P}=0.000$ & $\mathrm{P}=0.004$ & $\mathrm{P}=0.000$ \\
MEEM & $\mathrm{P}=0.001$ & $\mathrm{P}=0.000$ & $\mathrm{P}=0.619$ & $\mathrm{P}=0.209$ & $\mathrm{P}=0.000$ & $\mathrm{P}=0.001$ \\
FAR (FAS) & $\mathrm{P}=0.035$ & $\mathrm{P}=0.023$ & $\mathrm{P}=0.846$ & $\mathrm{P}=0.364$ & $\mathrm{P}=0.036$ & $\mathrm{P}=0.001$ \\
Animals & $\mathrm{P}=0.003$ & $\mathrm{P}=0.028$ & $\mathrm{P}=0.779$ & $\mathrm{P}=0.010$ & $\mathrm{P}=0.067$ & $\mathrm{P}=0.000$ \\
Errors/Attention & $\mathrm{P}=0.108$ & $\mathrm{P}=0.000$ & $\mathrm{P}=0.176$ & $\mathrm{P}=0.860$ & $\mathrm{P}=0.000$ & $\mathrm{P}=0.015$ \\
House & $\mathrm{P}=0.004$ & $\mathrm{P}=0.000$ & $\mathrm{P}=0.429$ & $\mathrm{P}=0.209$ & $\mathrm{P}=0.001$ & $\mathrm{P}=0.000$ \\
Clock & $\mathrm{P}=0.002$ & $\mathrm{P}=0.000$ & $\mathrm{P}=0.745$ & $\mathrm{P}=0.276$ & $\mathrm{P}=0.000$ & $\mathrm{P}=0.001$ \\
\hline
\end{tabular}

* Mann-Whitney test. Group 1: Controls ( $n=30$ ); Group 2: PGWIA (Parkinson group with anticholinergic) ( $n=11)$; Group 3: PGWOA (Parkinson group without anticholinergic) ( $n=19)$; Group 4: PGWOD (Parkinson group without depression ( $n=23)$; Group 5: PGWID (Parkinson group with depression) ( $n=07$ ). 
sult of a possible influence of anticholinergic drugs on the cognitive tests in patient groups and subgroups. Although not mentioned in the article, the patients were analyzed in separate groups (users and non-users of anticholinergic drugs in the Parkinson group). There was no significant difference between the groups (Table). When compared with the control group, a statistically significant difference was observed in all the tests for the anticholinergic users, except in the errors/attention test. However, there was a statistically significant difference between the control group and the group that did not use anticholinergics in all tests (Table).

Caixeta et al. point out that the Parkinson group with depression yielded scores similar to those for the Parkinson group without depression, and they attribute these values to the fact that the Parkinson group without depression was probably compromised by the use of anticholinergic drugs. It can be seen from Table that MADRS was significant, since this is a test for depression. The only difference between the groups occurred in the animals test. This could be because of greater difficulty in category rather than phonetic verbal fluency ${ }^{2}$.

Some antiparkinsonian drugs can have some effect on cognition and depression. Levodopa has limited or no antidepressant effect and can occasionally be responsible for depression. However, the reported frequency of depression before and after the start of levodopa therapy was similar. This does not support the idea that this drug may increase the frequency of depression, although the possibility that it plays a role in precipitating or exacerbating the condition cannot be definitively excluded ${ }^{3}$. Do- paminergic agonists can also affect mood and generally lead to an improvement in depressive symptoms. Mood changes in response to these drugs tend to vary more than the motor responses ${ }^{4,5}$. Drugs with a potential anticholinergic effect have little influence on mood changes, and although in some cases they can lead to mild euphoria, they are relatively ineffective as antidepressants. The possible effects on cognition can vary according to the stage of the disease and the extent to which the extranigral dopaminergic pathways are compromised ${ }^{6}$.

Diagnosis of depression in Parkinson's disease can be extremely complicated. The question remains as to whether it is the result of basic physiopathological mechanisms or secondary to motor impairment ${ }^{5,7}$.

\section{REFERENCES}

1. Piovezan MR, Teive HAG, Piovesan EJ, Mader MJ, Werneck LC. Congnitive function assessment in idiopathic Parkinson's disease. Arq Neuropsiquiatr 2007;65:942-946.

2. Lezak Md. Howieson Db, Loring Dw. Neuropsychological Assesment. Oxford University Press Inc, 2004

3. Cummings JL. Depression and Parkinson's disease: a review. Am J Psychiatry 1992;149:443-454.

4. Poewe W. Depression in Parkinson's disease. J Neurol 2007;254(Suppl 5):S49-S55.

5. Lemke MR. Antidepressant effects of dopamine agonists : Experimental and clinical findings. Nervenarzt 2007;78:31-38.

6. Huszonek JJ. Anticholinergic effects in a depressed parkinsonian patient. J Geriatr Psychiatry Neurol 1995;8:100-102.

7. Burn DJ. Depression in Parkinson's disease. Eur J Neurol 2002;9(Suppl 3):S44-S54.

Mauro Roberto Piovezan, Hélio Afonso Ghizoni Teive, Elcio Juliato Piovesan, Maria Joana Mader, Lineu Cesar Werneck

\section{GLOSSOPHARYNGEAL NEURALGIA WITH SYNCOPE AS A SIGN OF NECK CANCER RECURRENCE}

\section{TO THE EDITOR}

I have read the article (case report) "Glossopharyngeal neuralgia with syncope as a sign of neck cancer recurrence" by Reinaldo Teixeira Ribeiro et al.', and found it extremely interesting. I would like to give a historical contribution; not regarding the rare relationship between glossopharyngeal neuralgia with syncope and neck cancer, because authors approached this very well, but in respect to the following citation in the first paragraph of the discussion: "Among the Brazilian cases of classical glossopharyngeal neuralgia previously reported..." Here, the authors missed an opportunity to include Professor Pedro Sampaio's fundamental work on this issue.
The first and most important study in Brazil concerning glossopharyngeal neuralgia was made by Professor Pedro Sampaio when he made his Livre Docência Thesis to Universidade do Brasil in 1954, and published his results that same year in the Jornal Brasileiro de Neurologia ${ }^{2}$.

Pedro Sampaio made an extensive clinical study describing ten cases of glossopharyngeal neuralgia, experimental research utilizing eight dogs, and a broad bibliographic review. In respect to two of his patients; one with glossopharyngeal neuralgia and fainting sensations (case 9) and the other with concomitant tonic-clonic seizures (case 10), he created the term "neuralgia sinocarotidea" to denominated the algic form localized in the pos- 